\title{
TINJAUAN TERHADAP KONDISI DAERAH IRIGASI DESA GERINIS KOMPLEK, KABUPATEN SEKADAU
}

\author{
Khristiyani ${ }^{1}$, Stefanus Barlian Soeryamassoeka ${ }^{2}$, Dian Rahayu Jati ${ }^{1}$ \\ ${ }^{1}$ Program Studi Teknik Lingkungan Universitas Tanjungpura Pontianak \\ ${ }^{2}$ Program Studi Teknik Sipil Universitas Tanjungpura Pontianak \\ email: khristiyani.tobing@yahoo.co.id
}

\begin{abstract}
ABSTRAK
Daerah Irigasi Gerinis Kompek merupakan daerah irigasi yang berada di Kecamatan Nanga Taman, Kabupaten Sekadau. Berdasarkan data dari Dinas Pekerjaan Umum Sekadau tahun 2012, daerah irigasi Gerinis Kompek ini memiliki luas lahan sekitar $75 \mathrm{Ha}$, luas lahan potensial $60 \mathrm{Ha}$ dan luas lahan fungsional sekitar $45 \mathrm{Ha}$. Sumber air yang digunakan dalam daerah irigasi ini adalah sumber air yang berasal dari Sungai Merah. Berdasarkan analisa yang dilakukan dengan metode Mock, besarnya ketersediaan air (debit andalan) sebesar 134,5 It/detik, sedangkan kebutuhan air irigasinya sebesar 44,95 It/detik. Dari analisa imbangan air untuk daerah irigasi Gerinis Komplek diketahui bahwa daerah irigasi Gerinis Komplek memiliki ketersediaan air yang lebih banyak dari kebutuhan air irigasi yang diperlukan. Walaupun ketersediaan airnya mencukupi kebutuhan air irigasi, namun saluran irigasinya mengalami kerusakan termasuk saluran tersier kiri 4 yang tidak terairi. Hal ini dikarenakan pembangunan dimensi saluran yang lebih besar dibandingkan dengan kebutuhan air irigasi. Sehingga dilakukan penyelesaian secara teknis berupa desain dimensi saluran dan secara non teknis berupa konservasi.
\end{abstract}

Kata kunci: Daerah Irigasi Gerinis Komplek, metode Mock, efektifitas saluran

\begin{abstract}
Irrigation Area of Gerinis Kompek is an irrigation that located in subdstrict of Nanga Taman, Dist rict of Sekadau. Based on the data from the Department of Public Sekadau in 2012, this Komplek Gerinis $i$ rrigation area has 75 hectares land area, 60 hectares potential land area and 45 hectares functional land area. The water that is used in this irrigation area is the water source from the Red River. Based on the an alysis carried out by the Moc method, the number of water availability (discharge mainstay) is 134.5 liter /sec, while the irrigation water requirement is 44.95 liter/sec. From the analysis of the water balance for the complex gerinis irrigation Gerinis area known that the water availability of complex gerinis irrigation area water availability is more than the irrigation water demand that is required. Although the availabilit $y$ of water is sufficient for irrigation water, but the irrigation channels are damage including tertiary chan nel 4 which is not irrigated. This is because the construction of the channel dimensions are larger than the supply of irrigation water. So the settlement is done technically in form of channel dimensions design and non-technically in form of the conservation.
\end{abstract}

Keywords: complex gerinis irrigation area, mock method, the effectiveness of the channell 


\section{Pendahuluan}

Air merupakan salah satu kebutuhan pokok makhluk hidup yang sangat penting dalam kehidupan sehari-hari. Selain sebagai pemenuhan konsumsi air minum, air juga digunakan untuk keperluan dalam segala bidang, diantaranya pertanian, perikanan, industri, transportasi dan lain-lain (Mardonius,E, 2009). Kalimantan Barat memiliki areal pertanian yang tersebar di berbagai daerah di Kabupaten Pontianak, salah satunya di Kabupaten Sekadau, Kecamatan Nanga Taman.

Daerah Irigasi Gerinis Komplek memiliki luas 45 ha dan merupakan salah satu potensi pertanian yang diharapkan menunjang ketahanan pangan di Kabupaten Sekadau. Perubahan luas lahan sawah maupun lahan pertanian dari tahun 2009 ke tahun 2010 menjadi salah satu faktor dalam penurunan ketersediaan air. Sedangkan pada lahan bukan pertanian mengalami kenaikan di tahun 2010. Lahan bukan pertanian ini digunakan untuk perumahan, bangunan dan halaman sekitar. Hal ini jelas terlihat bahwa semakin tahun lahan yang semestinya digunakan untuk pertanian dialihkan kepembangunan atau dapat dikatakan mengalami perubahan tata guna lahan.

Dari permasalahan yang ada konservasi air menjadi pusat perhatian dalam pembangunan berkelanjutan. Sudah banyak penelitian dan kajian tentang manfaat konservasi, tetapi memasyarakatkan teknologi ini pada masyarakat untuk diimplementasikan secara berkelanjutan (sustainable) masih tetap menjadi angan-angan yang belum terwujud. Sehingga, konsep konservasi ini difokuskan apakah daerah tersebut akan dipertahankan, ditingkatkan atau diperbaiki.

\section{Metode Penelitian}

Penelitian ini berada di daerah irigasi Gerinis Komplek, Kecamatan Nanga Taman, Kabupaten Sekadau. Alat yang digunakan dalam penelitian ini antara lain, current meter, GPS, serta meteran.

\section{- Pengumpulan Data Dimensi Saluran Irigasi}

Ukur lebar penampang atas dan bawah dengan membentangkan tali/meteran melintang dari ujung satu sisi ke sisi lannya. Kemudian ukur kedalaman pada kondisi $1 / 4,1 / 2$ dan $3 / 4$ lebar penampang atas dan catat hasil pengukuran.

\section{- Pengumpulan Data Kecepatan Aliran}

Ukur kecepatan aliran pada beberapa 9 titik dari beberapa vertikal pada suatu penampang melintang dengan menggunakan alat ukur arus Current Meter.

\section{Hasil dan Pembahasan}

A. Permasalahan Yang Ada di Daerah Irigais Gerinis Komplek

- Analisa Ketersediaan Air

Analisa ketersediaan meliputi analisa evapotranspirasi dan analisa Mock dengan mengetahui sumber dan data seperti data hidrologi (curah hujan) dan klimatologi (temperatur udara, kelembaban udara, kecepatan angin, penyinaran matahari).

\section{- Analisa Evapotranspirasi}

Resume hasil analisa evapotranspirasi dari tahun 1985-2011 dapat dilihat pada tabel 1 berikut: 
Tabel 1. Resume Evapotranspirasi Tahun 1985-2011 (mm/hari)

\begin{tabular}{|c|c|c|c|c|c|c|c|c|c|c|c|c|}
\hline \multirow{2}{*}{ Tahun } & \multicolumn{12}{|c|}{ Bulan } \\
\hline & Jan & Feb & Mar & Apr & Mei & Jun & Jul & Agus & Sep & Okt & Nop & Des \\
\hline 1985 & 3,415 & 3,788 & 3,568 & 3,549 & 3,224 & 2,985 & 2,943 & 3,409 & 3,360 & 3,395 & 3,222 & 3,899 \\
\hline 1986 & 4,121 & 4,695 & 3,385 & 3,298 & 3,326 & 2,805 & 3,175 & 3,955 & 3,756 & 2,992 & 3,180 & 3,425 \\
\hline 1989 & 3,628 & 3,721 & 3,553 & 3,747 & 3,159 & 2,930 & 2,597 & 3,400 & 3,365 & 3,074 & 3,698 & 3,223 \\
\hline 1992 & 3,371 & 4,554 & 3,624 & 3,713 & 3,329 & 2,486 & 3,234 & 3,705 & 2,972 & 3,451 & 3,478 & 2,983 \\
\hline 1994 & 3,943 & 4,727 & 3,558 & 3,506 & 2,997 & 2,948 & 3,446 & 3,771 & 4,256 & 3,969 & 3,471 & 4,018 \\
\hline 1997 & 3,895 & 4,325 & 3,847 & 3,356 & 3,024 & 2,907 & 3,108 & 4,149 & 3,570 & 3,784 & 3,495 & 3,747 \\
\hline 1998 & 3,998 & 4,340 & 3,638 & 3,446 & 3,103 & 2,777 & 2,957 & 2,866 & 2,819 & 3,163 & 3,479 & 4,245 \\
\hline 1999 & 4,108 & 4,243 & 3,814 & 3,816 & 3,414 & 3,203 & 3,094 & 3,553 & 3,812 & 3,339 & 3,744 & 4,256 \\
\hline 2000 & 3,249 & 4,661 & 4,443 & 3,479 & 3,564 & 3,017 & 3,470 & 3,541 & 3,446 & 3,776 & 3,632 & 4,402 \\
\hline 2002 & 3,459 & 4,388 & 3,236 & 3,538 & 3,579 & 2,640 & 3,517 & 4,213 & 4,198 & 4,276 & 3,263 & 3,686 \\
\hline 2003 & 3,530 & 3,781 & 3,603 & 3,505 & 3,674 & 2,848 & 3,231 & 3,842 & 3,778 & 3,576 & 3,805 & 3,816 \\
\hline 2004 & 3,242 & 4,695 & 3,856 & 3,731 & 3,121 & 3,191 & 2,568 & 4,369 & 3,583 & 3,724 & 3,622 & 3,583 \\
\hline 2005 & 4,022 & 4,573 & 3,522 & 3,823 & 3,066 & 2,540 & 2,709 & 3,940 & 3,666 & 3,307 & 3,797 & 3,880 \\
\hline 2006 & 3,947 & 4,275 & 4,142 & 3,801 & 3,322 & 3,021 & 3,508 & 4,340 & 3,889 & 4,193 & 3,912 & 3,695 \\
\hline 2007 & 4,119 & 4,454 & 4,304 & 3,782 & 3,424 & 2,987 & 2,907 & 4,305 & 3,933 & 3,819 & 3,674 & 4,003 \\
\hline 2008 & 3,639 & 4,691 & 3,891 & 3,769 & 3,218 & 3,074 & 3,164 & 3,763 & 4,041 & 3,553 & 3,996 & 3,815 \\
\hline 2009 & 4,746 & 4,616 & 3,240 & 3,496 & 3,680 & 2,720 & 3,482 & 4,273 & 4,038 & 3,534 & 3,742 & 3,677 \\
\hline 2010 & 4,252 & 4,478 & 3,681 & 3,598 & 3,450 & 3,196 & 2,954 & 3,887 & 4,238 & 4,143 & 3,887 & 4,274 \\
\hline 2011 & 4,002 & 4,661 & 4,007 & 3,943 & 3,712 & 3,436 & 3,560 & 4,261 & 4,445 & 3,684 & 3,865 & 3,954 \\
\hline Jumlah & 72,687 & 83,667 & 70,912 & 68,895 & 63,388 & 55,712 & 59,625 & 73,542 & 71,165 & 68,755 & 68,962 & 72,580 \\
\hline Max & 4,746 & 4,727 & 4,443 & 3,943 & 3,712 & 3,436 & 3,560 & 4,369 & 4,445 & 4,276 & 3,996 & 4,402 \\
\hline Min & 3,242 & 3,721 & 3,236 & 3,298 & 2,997 & 2,486 & 2,568 & 2,866 & 2,819 & 2,992 & 3,180 & 2,983 \\
\hline $\begin{array}{l}\text { Rata- } \\
\text { rata }\end{array}$ & 3,826 & 4,404 & 3,732 & 3,626 & 3,336 & 2,932 & 3,138 & 3,871 & 3,746 & 3,619 & 3,630 & 3,820 \\
\hline
\end{tabular}

Nilai evapotranspirasi merupakan nilai kehilangan air yang terjadi dari tahun 1985-2011 pada daerah irigasi Gerinis Komplek. Dengan metode Penman, rumus yang digunakan dalam menentukan nilai evapotranspirasi adalah :

$$
\mathrm{ETP}=\frac{\delta}{\delta+\tau} \times \mathrm{Rn}+\frac{\tau}{(\delta+\tau)} \times\left[2,70 \times\left(1,0+0,010 \mathrm{U}_{2}\right)\left(\mathrm{e}_{\mathrm{s}}-\mathrm{e}_{\mathrm{a}}\right)\right]
$$

\section{- $\quad$ Analisa Mock}

Sama halnya dengan analisa evapotranspirasi, resume hasil analisa Mock dari tahun 19852011 dapat dilihat pada tabel 2 berikut ini :

Tabel 2. Resume Mock Tahun 1985-2011 (mm/hari)

\begin{tabular}{||l|l|l|l|l|l|l|l|l|l|l|l|l||}
\hline \hline \multirow{2}{*}{ Tahun } & \multicolumn{10}{|c||}{ Bulan } \\
\cline { 2 - 13 } & Jan & Feb & Mar & Apr & Mei & Jun & Jul & Agus & Sep & Okt & Nop & Des \\
\hline \hline 1985 & 0,317 & 0,368 & 0,234 & 0,198 & 0,170 & 0,071 & 0,063 & 0,125 & 0,183 & 0,217 & 0,364 & 0,177 \\
\hline 1986 & 0,114 & 0,114 & 0,227 & 0,296 & 0,145 & 0,126 & 0,071 & 0,031 & 0,028 & 0,307 & 0,361 & 0,339 \\
\hline 1989 & 0,289 & 0,355 & 0,270 & 0,180 & 0,210 & 0,115 & 0,224 & 0,186 & 0,224 & 0,376 & 0,224 & 0,441 \\
\hline
\end{tabular}




\begin{tabular}{|c|c|c|c|c|c|c|c|c|c|c|c|c|}
\hline \multirow{2}{*}{ Tahun } & \multicolumn{12}{|c|}{ Bulan } \\
\hline & Jan & Feb & Mar & Apr & Mei & Jun & Jul & Agus & Sep & Okt & Nop & Des \\
\hline 1992 & 0,373 & 0,220 & 0,243 & 0,177 & 0,101 & 0,227 & 0,066 & 0,091 & 0,312 & 0,235 & 0,266 & 0,508 \\
\hline 1994 & 0,097 & 0,074 & 0,178 & 0,179 & 0,215 & 0,070 & 0,058 & 0,042 & 0,018 & 0,127 & 0,219 & 0,124 \\
\hline 1997 & 0,179 & 0,206 & 0,146 & 0,257 & 0,227 & 0,097 & 0,083 & 0,034 & 0,083 & 0,081 & 0,237 & 0,231 \\
\hline 1998 & 0,178 & 0,200 & 0,188 & 0,216 & 0,191 & 0,134 & 0,100 & 0,300 & 0,512 & 0,432 & 0,301 & 0,138 \\
\hline 1999 & 0,164 & 0,235 & 0,180 & 0,155 & 0,198 & 0,060 & 0,176 & 0,192 & 0,140 & 0,346 & 0,264 & 0,181 \\
\hline 2000 & 0,446 & 0,213 & 0,137 & 0,264 & 0,209 & 0,175 & 0,099 & 0,224 & 0,334 & 0,257 & 0,368 & 0,194 \\
\hline 2002 & 0,408 & 0,254 & 0,456 & 0,402 & 0,211 & 0,385 & 0,108 & 0,101 & 0,044 & 0,022 & 0,368 & 0,379 \\
\hline 2003 & 0,335 & 0,456 & 0,314 & 0,384 & 0,170 & 0,256 & 0,159 & 0,171 & 0,147 & 0,239 & 0,248 & 0,305 \\
\hline 2004 & 0,470 & 0,169 & 0,234 & 0,224 & 0,242 & 0,075 & 0,333 & 0,098 & 0,228 & 0,193 & 0,307 & 0,345 \\
\hline 2005 & 0,176 & 0,180 & 0,283 & 0,200 & 0,273 & 0,415 & 0,399 & 0,145 & 0,240 & 0,340 & 0,265 & 0,268 \\
\hline 2006 & 0,214 & 0,277 & 0,144 & 0,219 & 0,185 & 0,205 & 0,093 & 0,039 & 0,109 & 0,055 & 0,176 & 0,321 \\
\hline 2007 & 0,186 & 0,241 & 0,126 & 0,190 & 0,172 & 0,229 & 0,303 & 0,087 & 0,189 & 0,195 & 0,346 & 0,240 \\
\hline 2008 & 0,400 & 0,211 & 0,275 & 0,234 & 0,350 & 0,248 & 0,240 & 0,208 & 0,183 & 306 & 0,292 &, 348 \\
\hline 2009 & 0,136 & 0,235 & 0,520 & 0,476 & 0,239 & 0,504 & 0,144 & 0,130 & 0,158 & 0,336 & 0,408 & 0,451 \\
\hline 2010 & 0,169 & 0,217 & 0,324 & 0,399 & 0,299 & 0,217 & 0,344 & 0,206 & 0,184 & 0,153 & 0,271 & 0,184 \\
\hline 2011 & 0,265 & 0,217 & 0,236 & 0,249 & 0,177 & 0,117 & 0,061 & 0,030 & 0,049 & 0,262 & 0,332 & 0,337 \\
\hline Jumlah & 3,545 & 3,104 & 3,418 & 3,613 & 2,916 & 3,022 & 2,559 & 1,931 & 2,515 & 3,134 & 3,944 & 3,692 \\
\hline Max & 0,470 & 0,456 & 0,520 & 0,476 & 0,350 & 0,504 & 0,399 & 0,300 & 0,512 & 0,432 & 0,408 & 0,508 \\
\hline Min & 0,097 & 0,074 & 0,126 & 0,155 & 0,101 & 0,060 & 0,058 & 0,030 & 0,018 & 0,022 & 0,176 & 0,124 \\
\hline $\begin{array}{l}\text { Rata- } \\
\text { rata }\end{array}$ & 0,259 & 0,234 & 0,248 & 0,258 & 0,210 & 0,196 & 0,164 & 0,128 & 0,177 & 0,236 & 0,296 & 0,290 \\
\hline
\end{tabular}

Analisa Mock digunakan dalam menghitung debit bulanan rata-rata, di mana rumus yang digunakan adalah (Dr. F. J. Mock) :

Calculated discharge $=$ total run off + catchment area.

Selanjutnya dengan menggunakan cara statistik, maka dihitung probabilitas debit andalan. Karena kajian yang dilakukan adalah kajian untuk air irigasi, maka probabilitas yang dihitung adalah probabilitas $80 \%$. Cara statistik yang digunakan adalah cara Weibull, maka didapatlah debit andalan probabilitas $80 \%$ seperti pada tabel 3 di bawah ini :

Tabel 3. Debit Andalan Probabilitas 80\% D.I Gerinis Komplek

\begin{tabular}{||l|c|c||}
\hline \multicolumn{1}{|c|}{ Bulan } & $\begin{array}{c}\text { Bulan } \\
\text { ( } \mathbf{m}^{3} / \text { detik) }\end{array}$ & $\begin{array}{c}\text { Bulan } \\
\text { (liter/detik) }\end{array}$ \\
\hline Januari & 0,1638 & 163,8 \\
\hline Februari & 0,1795 & 179,5 \\
\hline Maret & 0,1462 & 146,2 \\
\hline April & 0,1800 & 180,0 \\
\hline Mei & 0,1704 & 170,4 \\
\hline Juni & 0,0750 & 75,0 \\
\hline Juli & 0,0658 & 65,8 \\
\hline Agustus & 0,0392 & 39,2 \\
\hline September & 0,0487 & 48,7 \\
\hline Oktober & 0,1265 & 126,5 \\
\hline
\end{tabular}




\begin{tabular}{||l|c|c||}
\hline \hline Bulan & $\begin{array}{c}\text { Bulan } \\
\left(\mathrm{m}^{3} / \text { detik) }\right.\end{array}$ & $\begin{array}{c}\text { Bulan } \\
\text { (liter/detik) }\end{array}$ \\
\hline November & 0,2375 & 237,5 \\
\hline Desember & 0,1813 & 181,3 \\
\hline Rata-rata & 0,1345 & 134,5 \\
\hline
\end{tabular}

Dari tabel 3, didapat debit andalan untuk DI.Gerinis Komplek adalah sebesar 0,1345 $\mathrm{m}^{3} /$ detik. Debit yang didapat ini merupakan debit rencana untuk DI.Gerinis Komplek.

\section{- Analisa Kebutuhan Air Irigasi}

Analisa kebutuhan air irigasi ini meliputi analisa kebutuhan air di lahan (NFR) dan analisa kebutuhan air di bangunan pengambil (DR).

\section{- Kebutuhan Air Di Lahan (NFR)}

Pola tanam pada DI Gerinis Komplek adalah padi-padi dengan jenis varietas padi unggul. Berdasarkan perhitungan, maka besarnya kebutuhan air di sawah untuk setiap permulaan tanam yang berdasarkan NFR Maksimum adalah seperti pada tabel 4 berikut :

Tabel 4. NFR Maksimum Untuk Pola Tanam Padi-Padi

\begin{tabular}{|c|c|c|c|}
\hline No. & $\begin{array}{c}\text { Permulaan } \\
\text { Tanaman }\end{array}$ & $\begin{array}{c}\text { NFR } \\
\text { (mm/hari) }\end{array}$ & $\begin{array}{c}\text { NFR } \\
\text { (It/det/ha) }\end{array}$ \\
\hline \multirow{2}{*}{1} & \multirow{2}{*}{ Januari } & 3,09 & 0,36 \\
\hline & & 3,09 & 0,36 \\
\hline \multirow{2}{*}{2} & \multirow{2}{*}{ Februari } & 2,47 & 0,29 \\
\hline & & 2,47 & 0,29 \\
\hline \multirow{2}{*}{3} & \multirow{2}{*}{ Maret } & 3,13 & 0,36 \\
\hline & & 4,37 & 0,51 \\
\hline \multirow{2}{*}{4} & \multirow{2}{*}{ April } & 4,42 & 0,51 \\
\hline & & 4,80 & 0,56 \\
\hline \multirow{2}{*}{5} & \multirow{2}{*}{ Mei } & 4,85 & 0,56 \\
\hline & & 5,54 & 0,64 \\
\hline \multirow{2}{*}{6} & \multirow{2}{*}{ Juni } & 5,61 & 0,65 \\
\hline & & 5,61 & 0,65 \\
\hline \multirow{2}{*}{7} & \multirow{2}{*}{ Juli } & 3,09 & 0,36 \\
\hline & & 3,09 & 0,36 \\
\hline \multirow{2}{*}{8} & \multirow{2}{*}{ Agustus } & 2,47 & 0,29 \\
\hline & & 2,47 & 0,29 \\
\hline \multirow{2}{*}{9} & \multirow{2}{*}{ September } & 3,13 & 0,36 \\
\hline & & 4,37 & 0,51 \\
\hline \multirow{2}{*}{10} & \multirow{2}{*}{ Oktober } & 4,42 & 0,51 \\
\hline & & 4,80 & 0,56 \\
\hline \multirow{2}{*}{11} & \multirow{2}{*}{ November } & 4,85 & 0,56 \\
\hline & & 5,54 & 0,64 \\
\hline \multirow{2}{*}{12} & \multirow{2}{*}{ Desember } & 5,61 & 0,65 \\
\hline & & 5,61 & 0,65 \\
\hline
\end{tabular}

Berdasarkan tabel 4 di atas, maka nilai NFR tertinggi sebesar 0,65 liter/detik. Menurut Direktorat Jenderal Pengairan Departemen PU 1986 rumus yang digunakan dalam menghitung nilai NFR yang pada masa penyiapan lahan dihitung berdasarkan rumus : 
$\mathrm{NFR}=\mathrm{ETC}-\mathrm{Re}$

Sedangkan di luar masa penyiapan lahan menggunakan rumus :

$\mathrm{NFR}=\mathrm{ETC}+\mathrm{P}-\mathrm{Re}+\mathrm{WLR}$

- Kebutuhan Air Di Bangunan Pengambil (DR)

Dari hasil kebutuhan air di lahan, maka besarnya DR dapat dilihat pada tabel 5 berikut :

Tabel 5. Nilai DR pada DI Gerinis Komplek

\begin{tabular}{|c|c|c|c|c|}
\hline Bulan & $\begin{array}{c}\text { NFR } \\
\text { (lt/det/ha) }\end{array}$ & $\begin{array}{c}\text { A } \\
\text { (ha) }\end{array}$ & $\begin{array}{l}\text { Ef } \\
\% \\
\end{array}$ & $\begin{array}{c}\text { DR } \\
\text { (It/det) }\end{array}$ \\
\hline \multirow{2}{*}{ Januari } & 0,36 & 45 & 65 & 24,78 \\
\hline & 0,36 & 45 & 65 & 24,78 \\
\hline \multirow{2}{*}{ Februari } & 0,29 & 45 & 65 & 19,83 \\
\hline & 0,29 & 45 & 65 & 19,83 \\
\hline \multirow{2}{*}{ Maret } & 0,36 & 45 & 65 & 25,04 \\
\hline & 0,51 & 45 & 65 & 35,03 \\
\hline \multirow{2}{*}{ April } & 0,51 & 45 & 65 & 35,43 \\
\hline & 0,56 & 45 & 65 & 38,44 \\
\hline \multirow{2}{*}{ Mei } & 0,56 & 45 & 65 & 38,87 \\
\hline & 0,64 & 45 & 65 & 44,43 \\
\hline \multirow{2}{*}{ Juni } & 0,65 & 45 & 65 & 44,95 \\
\hline & 0,65 & 45 & 65 & 44,95 \\
\hline \multirow{2}{*}{ Juli } & 0,36 & 45 & 65 & 24,78 \\
\hline & 0,36 & 45 & 65 & 24,78 \\
\hline \multirow{2}{*}{ Agustus } & 0,29 & 45 & 65 & 19,83 \\
\hline & 0,29 & 45 & 65 & 19,83 \\
\hline \multirow{2}{*}{ September } & 0,36 & 45 & 65 & 25,04 \\
\hline & 0,51 & 45 & 65 & 35,03 \\
\hline \multirow{2}{*}{ Oktober } & 0,51 & 45 & 65 & 35,43 \\
\hline & 0,56 & 45 & 65 & 38,44 \\
\hline \multirow{2}{*}{ November } & 0,56 & 45 & 65 & 38,87 \\
\hline & 0,64 & 45 & 65 & 44,43 \\
\hline \multirow{2}{*}{ Desember } & 0,65 & 45 & 65 & 44,95 \\
\hline & 0,65 & 45 & 65 & 44,95 \\
\hline
\end{tabular}

Dari tabel 5 di atas, dapat dilihat besarnya kebutuhan air pada DI Gerinis Komplek adalah sebesar $44,95 \mathrm{It} /$ det.

Setelah mengetahui dan membandingkan debit ketersediaan dan kebutuhan air di DI Gerinis Komplek, maka ketersediaan air di Daerah Irigasi Gerinis Komplek masih mencukupi untuk melayani kebutuhan air irigasi. Namun terkadang air irigasi ini masih mengalami kekurangan pada daerah-daerah tertentu.

\section{- Efektifitas Saluran DI Gerinis Komplek}

Dengan mengetahui debit rencana dan debit kapasitas saluran, maka dapat diketahui efektifitas saluran di daerah tersebut seperti pada tabel 6 berikut : 
Tabel 6. Efektifitas Saluran DI Gerinis Komplek

\begin{tabular}{||l|c|c|c||}
\hline \multicolumn{1}{|c|}{ Saluran } & $\begin{array}{c}\text { Qkap } \\
\text { (lt/dt) }\end{array}$ & $\begin{array}{c}\text { Qrenc } \\
\text { (lt/dt) }\end{array}$ & Efektifitas \\
\hline Primer Kanan 1 & 18,50 & 18,85 & 0,93 \\
\hline Sekunder Kanan 2 & 10,25 & 4,31 & 0,35 \\
\hline Primer Kiri 1 & 19,31 & 22,93 & 0,96 \\
\hline Sekunder Kiri 2 & 10,26 & 14,27 & 1,09 \\
\hline Tersier Kanan 1 & 5,28 & 4,93 & 0,82 \\
\hline Tersier Kanan 2 & 5,64 & 7,73 & 1,04 \\
\hline Tersier Kanan 3 & 4,57 & 2,70 & 0,56 \\
\hline Tersier Kanan 4 & 3,62 & 1,18 & 0,30 \\
\hline Tersier Kiri 1 & 5,38 & 1,46 & 0,24 \\
\hline Tersier Kiri 2 & 5,61 & 4,90 & 0,82 \\
\hline Tersier Kiri 3 & 8,69 & 10,39 & 1,10 \\
\hline Tersier Kiri 4 & 0,00 & 2,46 & rusak \\
\hline
\end{tabular}

Dapat dilihat bahwa rata-rata saluran Daerah Irigasi Gerinis tidak efektif karena saluran yang memiliki angka tingkat efektifitas lebih kecil dari 1 terjadi pembangunan saluran dimensi yang terlalu besar sehingga mengalami pemborosan, sedangkan saluran yang memiliki angka tingkat efektifitas lebih besar dari 1 terjadi pembangunan saluran dengan dimensi yang terlalu kecil sehingga kapasitas saluran tidak mencukupi untuk mengalirkan debit yang direncanakan untuk kebutuhan air di areal pelayanan. Selain dari ketidakefektifan saluran, keadaan diperburuk dengan adanya kebocoran pada saluran irigasi. Kebocoran paling besar berada pada saluran tersier kiri 4, dimana pada saluran ini mengalami kerusakan dikarenakan tidak ada air yang mengalir atau dapat dikatakan kering. Untuk menyelesaikan permasalahan tersebut dapat dilakukan dengan langkah teknis dan nonteknis.

\section{B. Penyelesaian Secara Teknis}

Ketidakefektifan saluran dapat diperbaiki dengan mendesain ulang dimensi saluran. Dengan mengetahui $a, b$, dan $h$ pada masing-masing saluran, maka desain dimensi saluran yang baru untuk DI Gerinis Komplek terlihat pada tabel 7 berikut :

Tabel 7. Desain Dimensi Saluran

\begin{tabular}{|c|c|c|c|c|c|c|c|c|c|c|c|c|}
\hline Saluran & $\mathrm{a}(\mathrm{cm})$ & $\mathrm{b}(\mathrm{cm})$ & $\mathrm{h}(\mathrm{cm})$ & $\mathrm{Q}$ renc(t/dt) & $\mathrm{Q} \operatorname{renc}\left(\mathrm{m}^{3} / \mathrm{dt}\right)$ & $\mathrm{A}\left(\mathrm{m}^{2}\right)$ & $\begin{array}{c}\text { Vrenc } \\
(\mathrm{m} / \mathrm{dt})\end{array}$ & $\mathrm{m}$ & $\mathrm{P}(\mathrm{m})$ & $\mathrm{R}(\mathrm{m})$ & $\mathrm{K}$ & $\mathrm{i}$ \\
\hline Primer Kanan 1 & 1,45 & 0,65 & 0,40 & 18,85 & 0,019 & 0,420 & 0,045 & 1 & 1,781 & 0,24 & 35 & 0,000000001693 \\
\hline Sekunder Kanan 1 & 1,32 & 0,60 & 0,36 & 4,31 & 0,004 & 0,346 & 0,012 & 1 & 1,618 & 0,21 & 35 & 0,000000000088 \\
\hline Primer Kiri 1 & 1,42 & 0,62 & 0,40 & 22,93 & 0,023 & 0,408 & 0,056 & 1 & 1,751 & 0,23 & 35 & 0,0000000002531 \\
\hline Sekunder Kiri 1 & 1,34 & 0,58 & 0,38 & 14,27 & 0,014 & 0,365 & 0,039 & 1 & 1,655 & 0,22 & 35 & 0,0000000000984 \\
\hline Tersier Kanan 1 & 1,10 & 0,54 & 0,28 & 4,93 & 0,005 & 0,230 & 0,021 & 1 & 1,332 & 0,17 & 35 & 0,0000000000111 \\
\hline Tersier Kanan 2 & 1,06 & 0,50 & 0,28 & 7,73 & 0,008 & 0,218 & 0,035 & 1 & 1,292 & 0,17 & 35 & 0,0000000000278 \\
\hline Tersier Kanan 3 & 1,08 & 0,54 & 0,27 & 2,70 & 0,003 & 0,219 & 0,012 & 1 & 1,304 & 0,17 & 35 & 0,000000000033 \\
\hline Tersier Kanan 4 & 1,05 & 0,53 & 0,26 & 1,18 & 0,001 & 0,205 & 0,006 & 1 & 1,265 & 0,16 & 35 & 0,000000000006 \\
\hline Tersier Kiri 1 & 1,20 & 0,53 & 0,27 & 1,46 & 0,001 & 0,216 & 0,007 & 1 & 1,294 & 0,17 & 35 & 0,0000000000010 \\
\hline Tersier Kiri2 & 1,20 & 0,54 & 0,28 & 4,90 & 0,005 & 0,230 & 0,021 & 1 & 1,332 & 0,17 & 35 & 0,0000000000110 \\
\hline Tersier Kiri3 3 & 1,50 & 0,70 & 0,27 & 10,39 & 0,010 & 0,262 & 0,040 & 1 & 1,464 & 0,18 & 35 & 0,0000000000439 \\
\hline Tersier Kiri4 4 & 1,20 & 0,54 & 0,15 & 2,46 & 0,002 & 0,104 & 0,024 & 1 & 0,964 & 0,11 & 35 & 0,0000000000020 \\
\hline
\end{tabular}


Dari tabel 7 di atas, terlihat bahwa debit rencana untuk desain dimensi yang baru ini berbeda dengan debit kapasitas pada tabel 6 . Sehingga, efektifitas saluran setelah di desain adalah seperti pada tabel 8 berikut :

Tabel 8. Efektifitas Desain Saluran

\begin{tabular}{|c|c|c|c|}
\hline Saluran & $\begin{array}{c}\text { Qkap } \\
\text { (lt/dt) }\end{array}$ & $\begin{array}{c}\text { Q renc } \\
\text { (lt/dt) }\end{array}$ & Efektifitas \\
\hline Primer Kanan 1 & 18,85 & 18,85 & 1,00 \\
\hline Sekunder Kanan 2 & 4,31 & 4,31 & 1,00 \\
\hline Primer Kiri 1 & 22,93 & 22,93 & 1,00 \\
\hline Sekunder Kiri 2 & 14,27 & 14,27 & 1,00 \\
\hline Tersier Kanan 1 & 4,93 & 4,93 & 1,00 \\
\hline Tersier Kanan 2 & 7,73 & 7,73 & 1,00 \\
\hline Tersier Kanan 3 & 2,70 & 2,70 & 1,00 \\
\hline Tersier Kanan 4 & 1,18 & 1,18 & 1,00 \\
\hline Tersier Kiri 1 & 1,46 & 1,46 & 1,00 \\
\hline Tersier Kiri 2 & 4,90 & 4,90 & 1,00 \\
\hline Tersier Kiri 3 & 10,39 & 10,39 & 1,00 \\
\hline Tersier Kiri 4 & 2,46 & 2,46 & 1,00 \\
\hline
\end{tabular}

Dari tabel 8 di atas dapat dilihat bahwa debit (Q) kapasitas yang telah didesain ulang dimensinya memiliki nilai yang sama dengan debit (Q) yang direncanakan sehingga keefektifitasan saluran dapat diperoleh.

\section{Penyelesaian Secara Teknis}

Sedangkan langkah nonteknis dapat dilakukan dengan membuat suatu konsep konservasi yang dapat menjaga ketersediaan air agar tidak mengalami penurunan yang signifikan. Adapun kegiatan konservasi yang dilakukan adalah upaya perbaikan di beberapa bidang sebagai berikut:

- Usaha Tani

Peran serta petani-petani tidaklah lepas dalam membantu kegiatan konservasi air di daerah irigasi Gerinis Komplek. Hal ini dikarenakan petanilah yang paling sering berada di daerah irigasi tersebut. Meningkatkan kesadaran petani akan pentingnya konservasi air dapat dilakukan dengan melibatkan masyarakat langsung dalam program konservasi air. Untuk itu, konservasi yang harus dilakukan dalam usaha tani antara lain (Sukmana, 1996) :

- Meningkatkan kesadaran petani akan pentingnya konservasi air

- Meningkatkan pengetahuan dan wawasan petani akan manfaat konservasi air melalui penyuluhan

- Membentuk Perkumpulan Petani Pemakai Air (P3A)

\section{- Sarana Dan Prasarana irigasi}

Pemberian air irigasi memerlukan sarana dan prasarana irigasi yang memadai. Sarana dan prasarana tersebut dapat berupa, bendungan, saluran primer dan sekunder, dan saluran tersier. Terganggunya atau rusaknya salah satu bangunan-bangunan irigasi akan mempengaruhi kinerja sistem yang ada, sehingga efisiensi dan efektifitas irigasi menjadi menurun. Apabila kondisi ini dibiarkan terus dan tidak segera diatasi, maka akan berdampak terhadap penurunan produksi pertanian yang diharapkan, dan berimplikasi negatif terhadap kondisi pendapatan petani dan keadaan sosial, ekonomi disekitar lokasi. Melakukan perawatan dan pengawasan yang intens diharapkan dapat menjadi solusi dalam langkah konservasi ini. Pengawasan tersebut seperti 
kontrol dari pemerintah setempat. Selain itu, membuat embung juga dapat dilakukan dalam konservasi ini. Dari permasalahan tersebut, konservasi yang dapat dilakukan menurut UU No.7 tahun 2004 tentang Sumber Daya Air yaitu dengan melakukan pengaturan sarana dan prasarana. Dengan memperhatikan sarana dan prasarana tersebut diharapkan dapat meminimalisir kehilangan air karena bocoran atau rembesan air irigasi.

- Daerah Aliran Sungai (DAS)

DAS bagian hulu mempunyai peran penting, terutama sebagai tempat peyedia air untuk dialirkan ke bagian hilirnya. Oleh karena itu bagian hulu DAS seringkali mengalami konflik kepentingan dalam penggunaan lahan, terutama untuk kegiatan pertanian. Pada prinsipnya, DAS bagian hulu dapat dilakukan dengan usaha konservasi yang mencakup aspek-aspek yang berhubungan dengan suplai air. Peran strategis DAS sebagai unit perencanaan dan pengelolaan sumber daya semakin nyata pada saat DAS tidak dapat berfungsi optimal sebagai media pengatur tata air dan penjamin kualitas air yang dicerminkan dengan terjadinya banjir dan kekeringan yang tinggi. Hai ini erta kaitannya dengan tata guna lahan dan tutupan lahan sehingga diperlukan suatu pengelolaan dalam rangka konservasi sumber daya air. Menurut Notohadiprawiro 1981, konservasi yang dapat dilakukan pada Daerah Aliran Sungai (DAS) antara lain :

- Meningkatkan daya dukung DAS (Daerah Aliran Sungai) di hulu guna menerima, menyimpan selama mungkin, dan menyalurkan air hujan ke daerah hilir

- Menghutankan kembali lahan-lahan gundul

- Memonitor dan mengevaluasi daya tampung waduk atau bendungan

Konsep konservasi air di daerah irigasi Gerinis Komplek diharapkan dapat mempertahankan daerah yang sudah ada dengan memperbaiki kondisi-kondisi yang dapat mengakibatkan penurunan tersebut.

\section{Kesimpulan}

Daerah irigasi Gerinis Komplek cukup memiliki ketersediaan air, di mana besarnya ketersediaan air (debit andalan) sebesar 134,5 It/detik, sedangkan kebutuhan air irigasinya sebesar 44,95 It/detik. Namun, daerah irigasi ini memiliki masalah pada saluran irigasinya yang tidak efektif sehingga petak sawah terjauh tidak terairi. Sehingga, solusi teknis dari ketidakefektifan saluran adalah dengan mendesain dimensi saluran, sedangkan solusi non teknisnya berupa konsep konservasi.

\section{Ucapan Terima Kasih}

Dalam penelitian dan penulisan jurnal ini penulis mengucapkan terima kasih kepada kedua orang tua. Terima kasih kepada bapak Stefanus Barlian Soeryamassoeka, ST., MT dan ibu Dian Rahayu Jati ST., M.Si selaku dosen pembimbing, serta kepada ibu Dr. Ir. Hj. Kartini MT dan bapak H.Kiki Prio Utomo,ST., M.Sc selaku dosen penguji yang telah memberikan masukan dan koreksi yang sangat bermanfaat dalam penyelesaian penelitian ini. Penulis juga mengucapkan terima kasih kepada teman-teman atau pihak-pihak yang terlibat dalam penelitian ini yang tidak dapat disebutkan satu per satu .

\section{Daftar Pustaka}

Departemen Pekerjaan Umum Direktorat Jenderal Pengairan,1986, Standar Perencanaan Irigasi KP-06. Jakarta: Badan Penerbit Pekerjaan Umum.

Mardonius, E. 2009. Kajian Konservasi Air Di Daerah Irigasi Jagu Melancar. Mahasiswa Teknik Sipil Fakultas Teknik Universitas Tanjungpura, Pontianak. Universitas Tanjungpura. 
Mock, F.J. 1973. Land Capability Appraisal Indonesia. Water Avaibility Appraisal. Report Prepared for the Land Capability Appraisal Project. Bogor-Indonesia.

Notohadiprawiro, T. 1981. Jurnal Pengelolaan Daerah Aliran Sungai dan Program Penghijauan. Jurusan IImu Tanah. Fakultas Pertanian: UGM.

Sukmana, S. 1996. Teknik Konservasi Tanah Dalam Penanggulangan Degradasi Tanah Pertanian Lahan Kering.

Undang-undang No.7 Tahun 2004 Tentang Sumber Daya Air. Sekretariat Negara. Jakarta. 